\title{
Hypersomnia Associated with Bilateral Posterior Hypothalamic Lesion
}

\section{A Polysomnographic Case Study}

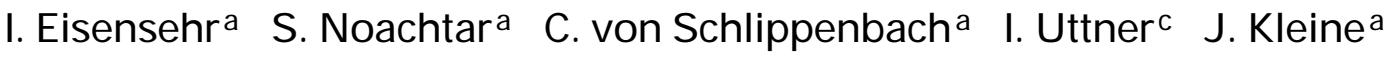 \\ K. Seelos ${ }^{b}$ C. Helmchend
}

Departments of a Neurology and ${ }^{b}$ Neuroradiology, University of Munich, Munich, cDepartment of Neurology, University of UIm, Ulm, and dDepartment of Neurology, University of Lübeck, Lübeck, Germany

\section{Key Words \\ Hypothalamus · Sleep · Polysomnography}

\begin{abstract}
We examined an obese 58 -year-old patient with a bilateral posterior hypothalamic lesion of unknown etiology. A 24-hour polysomnography revealed a markedly increased total sleep time (17.6 h). During daytime, only 3 continuous wake phases occurred. REM periods occurred only between 5 p.m. and 6 a.m. We conclude from our results that, similar to the results from animal experiments, the posterior hypothalamus in humans plays a critical role in the maintenance of wakefulness.
\end{abstract}

Copyright @2003S. Karger AG, Basel

\section{Objectives}

It is postulated from animal studies that the posterior hypothalamus is important for maintaining wakefulness [1], whereas the anterior hypothalamus promotes sleep [2] and regulates the sleep-wake cycle [3]. To elucidate the role of the posterior hypothalamus in circadian rhythm with regard to sleep in humans, we examined a patient with a bilateral posterior hypothalamic lesion of unknown etiology using polysomnography (PSG). This, to the best of our knowledge, has not been done before.

\section{Case Report}

\section{Patient History}

On first admission this obese 58-year-old female patient (BMI: $46.5 \mathrm{~kg} / \mathrm{m}^{2}$ ) reported a 2 -month history of circadian temperature peaks in the evening (up to $39.6^{\circ} \mathrm{C}$ ), progressive daytime sleepiness, apathy, irritability and hyperphagia.

Neurological, physical and psychiatric examinations were normal. Blood pressure was 180/110 mm Hg. Ophthalmologic exploration revealed concentric visual field loss of $30^{\circ}$ in both eyes. Cranial MRI showed bilateral, Gadolinium-enhanced lesions in the posterior hypothalamus. Thoracic and abdominal computed tomographies, echocardiography, microbiological blood, urine and stool cultures were normal.

Five months after the first admission the clinical symptoms were still slowly progressive. Due to the homogeneous form and symmetry of the hypothalamic lesion, sarcoidosis was suspected and the patient was treated with methylprednisolone (initially $100 \mathrm{mg} / \mathrm{day}$, tapering down to a maintenance dose of $2 \mathrm{mg}$ every other day for 7 months) and azathioprine (100 mg/day). Azathioprine had to be stopped after 3 months because of a marked increase of liver enzymes [alkaline phosphatase (AP): $265 \mathrm{U} / 1 ; \gamma$-glutamyl transpeptidase: $650 \mathrm{U} / \mathrm{l}$; glutamic pyruvic transaminase: $64 \mathrm{U} / 1$; glutamic oxalacetic transaminase (GOT): $47 \mathrm{U} / 1$; lactate dehydrogenase: $382 \mathrm{U} / 1$ ].

Five months after the beginning of immunosuppressive therapy, hypersomnia and weight gain were still marked. Temperature peaks still occurred mostly in the evening. Visual fields improved to $50^{\circ}$ of concentric impairment.

One year after her first admission she died at home of unknown causes after having gained about $35 \mathrm{~kg}$ of weight. She had spent the last few months sleeping in bed most of the time. Her husband did not permit post-mortem pathological examination.

\begin{tabular}{ll}
\hline KARGER & $\begin{array}{l}\text { ( ) 2003 S. Karger AG, Basel } \\
0014-3022 / 03 / 0493-0169 \$ 19.50 / 0\end{array}$ \\
$\begin{array}{l}\text { Fax +4161306 1234 } \\
\text { E-Mail karger@karger.ch } \\
\text { www.karger.com }\end{array}$ & $\begin{array}{l}\text { Accessible online at: } \\
\text { www.karger.com/ene }\end{array}$
\end{tabular}

Ilonka Eisensehr, MD

Department of Neurology, Klinikum Grosshadern

Ludwig Maximilian University Munich

Marchioninistrasse 15, D-81377 Munich (Germany)

Tel. +49 897095 3904, Fax +4989 7095 3677, E-Mail eisen@nefo.med.uni-muenchen.de 


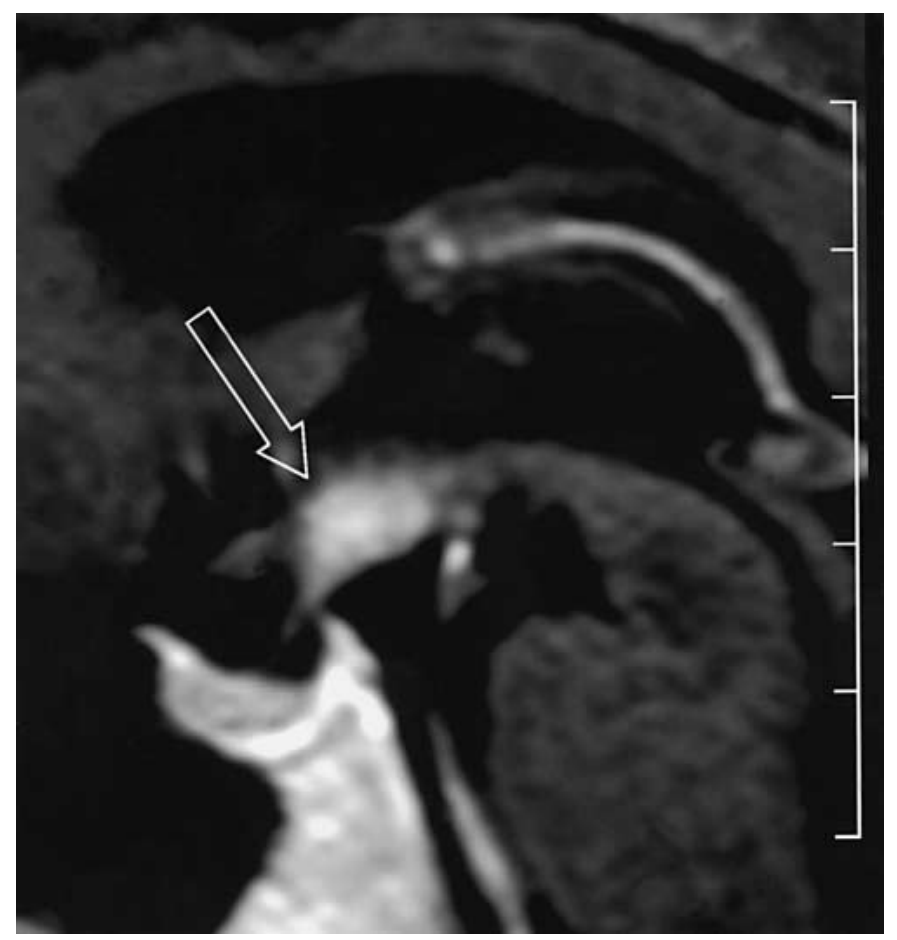

Fig. 1. Cranial MRI (sagittal $T_{1}$-weighted image) showing the contrast-enhanced lesion in the posterior hypothalamus on first admission (arrow).

\section{Cranial MRI}

Serial MRI, including $\mathrm{T}_{1^{-}}, \mathrm{T}_{2}$ - and proton-weighted images, with and without Gadolinium, were performed 7 times. The initial MRI showed a bilateral, Gadolinium-enhanced lesion in the posterior hypothalamic nuclei, and tuberally and centrally (fig. 1). Lateral and anterior hypothalamic structures were not affected. Five months after the first admission but before the beginning of immunosuppressive therapy, the lesion had discretely increased in size but did not invade hypothalamic structures near or anterior to the optic chiasm. Five months after the beginning of immunosuppressive therapy, cranial MRI showed a reduction of the contrast enhancement and size of the hypothalamic lesions as well as a widening of the third ventricle, most likely due to atrophy.

\section{Sleep Studies}

A digital system (Brainlab, Schwarzer, Munich, Germany) was used to record the PSG. The study began around 4 p.m. and ended around 4 p.m. the next day; electroencephalogram, electro-oculogram, electromyogram, electrocardiogram and breathing parameters were recorded and scored, as recently published in detail [4].

\section{Sleep Analysis}

A 24-hour PSG was performed 5 months after the start of immunosuppressive therapy. Total sleep time (TST) was $17.6 \mathrm{~h}, 7.4 \%$ of which was stage I, $34.1 \%$ stage II, $21 \%$ stage III, $8.5 \%$ stage IV and $19.9 \%$ REM stage. There were only three continuous wake phases of more than $30 \mathrm{~min}$, all during the daytime and lasting less than $1 \mathrm{~h}$.
REM sleep did not occur between 7 a.m. and 5 p.m. There was no significant increase of periodic limb movements or apneas/hypopneas during sleep.

\section{Results}

Blood analyses were performed on first admission and several times during and after 5 months of immunosuppressive therapy.

\section{Endocrinology}

Thyrotropin-releasing factor and growth hormone releasing factor tests were within the normal range in the morning. The cortisol profile (8 a.m., 2 p.m., 7 p.m., 11 p.m.) was also normal. Morning analyses of thyroid hormones, estradiol, testosterone, luteotropic hormone (LH), follicle-stimulating hormone (FSH), human chorionic gonadotropin, and somatomedin $\mathrm{C}$ also revealed normal results. Increased morning prolactin (table 1) indicated dysfunction of the tuberoinfundibular hypothalamic region [5]. Possibly due to the elevated prolactin level, $\mathrm{LH}$ and FSH secretion could not be stimulated with luteotropic hormone-releasing factor in the morning.

Five months after the beginning of immunosuppressive therapy, prolactin was still elevated (table 1) and the other endocrinological parameters did not change.

\section{Serological Parameters}

For pathological values see table 1. Values for angiotensin-converting enzyme, C-reactive protein, electrolytes, $\mathrm{HbA}_{1 \mathrm{c}}$, uric acid, triglycerides, bilirubin, pseudocholinesterase, lipase, creatine kinase, Quick, PTT, AP, B2 microglobulin, A2 haptoglobin, $\alpha$-fetoprotein, GOT, serum and urinary osmolalities, and serum electrophoresis were normal at different times during the day. Serological analyses for cytomegalovirus (including clonab ${ }^{\circledR}$ test), Lyme, syphilis, Herpes simplex, hepatitis A, B, C, and Epstein-Barr virus were negative.

\section{Blood Cell Count}

Pathological values are listed in table 1; the other values were within normal range.

\section{CSF}

CSF analyses revealed a lymphocytic inflammatory process on first admission, which was absent 5 months after the beginning of the immunosuppressive therapy (table 1). 
Table 1. Pathological laboratory tests

\begin{tabular}{lcl}
\hline & On first admission & 5 Months OT \\
\hline Prolactin, ng/ml & 81.8 & 83.4 \\
Glucose, mg/dl & 169 & normal \\
$\gamma$-GT, U/1 & 60 & normal \\
GPT, U/l & 35 & normal \\
MCH, pg & 34.5 & normal \\
Erythrocytes & $4.13 \mathrm{~T} / 1$ & normal \\
CSF cells, $\mu 1$ & 41 & normal \\
$\quad$ Lymphocytes, $\%$ & 86 & \\
$\quad$ Monocytes, \% & 10 & \\
Lymphoids, \% & 4 & positive in CSF only \\
OCBs & positive in CSF and serum & negative \\
CSF ACE & negative & \\
\hline
\end{tabular}

OT = After onset of immunosuppressive therapy; $\mathrm{ACE}$ = angiotensin-converting enzyme; $\mathrm{CSF}=$ cerebrospinal fluid $; \gamma$-GT $=\gamma$-glutamyl transpeptidase $; \mathrm{GPT}=$ glutamic pyruvic transaminase; $\mathrm{MCH}=$ mean corpuscular hemoglobin; $\mathrm{OCBs}=$ oligoclonal bands.

\section{Neuropsychological Examination}

Neuropsychological examination was performed on first admission and 5 months after the beginning of immunosuppressive therapy. The patient showed consistent memory deficits as regards verbal learning as well as retrograde amnesia for the last 10 years. Her memory span for words was initially highly reduced but returned to normal 5 months after beginning immunosuppressive therapy. Orientation as to time and place was limited, and there was a pronounced attention deficit with cognitive slowing. In addition, an impairment of executive functions was seen. The patient's awareness of her disabilities was clearly reduced.

\section{Temperature}

Temperature was usually normal in the morning hours (around $37^{\circ} \mathrm{C}$ ) and rose in the late afternoon or evening, reaching peaks up to $39.6^{\circ} \mathrm{C}$.

\section{Conclusions}

\section{Hypersomnia}

This case study provides the first reported full-day polysomnographic evaluation of a human with bilateral posterior hypothalamic lesion. The main finding in our patient was severe hypersomnia with preserved sleepwake cycle.

Bilateral anterior hypothalamic lesion, however, has been associated with disrupted temporal patterns of the sleep-wake cycle in which there were periods of daytime hypersomnolence and increased body temperature [6]. Markedly increased TST in our patient reflected hypersomnia. The circadian sleep-wake cycle was preserved: only short awakenings occurred during the night; all REM phases were restricted to the night period, and the longest periods of wakefulness occurred during daytime. Our finding of hypersomnia with preserved sleep-wake cycle in bilateral posterior hypothalamic lesion in the human is in keeping with results from animal studies: the suprachiasmatic nucleus in the anterior hypothalamus of the rat is considered the main pacemaker for the sleep-wake cycle [3], whereas the posterior hypothalamus of the rat is supposed to function as a waking center $[1,2]$.

\section{Hyperthermia}

Hyperthermia is a common and typical feature of lesions of the tuberoinfundibular region of the hypothalamus [7], which was also lesioned in our patient. Our patient still showed some circadian variability of body temperature, which suggests an intact circadian pacemaker for body temperature in the anterior hypothalamus. Schwartz et al. [8] demonstrated a change in daily temperature rhythm without increase in mean daily temperature in a patient with an anterior hypothalamic lesion and hypothesized that this was due to the disturbed function of this region.

\section{Hyperphagia}

Our results are supported by animal experiments showing that hyperphagia is associated with bilateral posterior hypothalamic lesions in rats [9]. 


\section{Neuropsychology}

Memory deficits as seen in our patient may be associated with the degeneration of the dorsal medial hypothalamic nucleus [10], but they were also seen after lesions of the anterior hypothalamus [6]. A disruption of the lateral amygdalofugal pathways projecting to the region of ventral medial nucleus was discussed as a possible explanation.

\section{Conclusion}

Pathological findings in our patient were caused most probably by the location of the CNS lesion bilaterally in the posterior hypothalamus. Systemic influences of sarcoidosis have not been suggested to lead to hypersomnia, hyperphagia, hyperthermia, and memory deficits. Moreover, these symptoms already existed before the initiation of immunosuppressive therapy, conclusively excluding the possibility that immunosuppressive therapy would be the cause of the complaints.

Our case supports the animal experiment-based hypothesis that the posterior hypothalamus works as a center for maintenance of wakefulness. Homologous to the rat hypothalamus, the posterior hypothalamus in humans does not seem to be necessary for a functioning sleepwake cycle. Our results further support the hypothesis of an important role of the human posterior hypothalamus in regulating food intake, keeping the body temperature within the normal range and in maintaining intact memory as well as executive functions.

\section{References}

1 Lin JS, Sakai K, Vanni-Mercier G, Jouvet M: A critical role of the posterior hypothalamus in the mechanisms of wakefulness determined by microinjection of muscimol in freely moving cats. Brain Res 1989;479:225-240.

2 Sallanon M, Denoyer M, Kitahama K, Aubert C, Gay N, Jouvet M: Long-lasting insomnia induced by preoptic neuron lesions and its transient reversal by muscimol injection into the posterior hypothalamus in the cat. Neuroscience 1989;32:669-683.

3 Rusak B, Zucker I: Neural regulation of circadian rhythms. Physiol Rev 1979;59:449-526.
4 Eisensehr I, Ehrenberg BL, Noachtar S, Korbett K, Byrne A, McAuley A, Palabrica T: Platelet activation, epinephrine, and blood pressure in obstructive sleep apnea syndrome. Neurology 1998;51:188-195.

5 Moore KE: Interactions between prolactin and dopaminergic neurons. Biol Reprod 1987;36: 47-58.

6 Cohen RA, Albers HE: Disruption of human circadian and cognitive regulation following a discrete hypothalamic lesion: A case study. Neurology 1992;41:726-729.
7 Carmel PW: Surgical syndromes of the hypothalamus. Clin Neurosurg 1980;27:133-159.

8 Schwartz WJ, Bosis NA, Hedley-Whyte ET: A discrete lesion of the ventral hypothalamus and optic chiasm that disturbed the daily temperature rhythm. J Neurol 1986;233:1-4.

9 Sclafani A, Berner CN: Hyperphagia and obesity produced by parasagittal and coronal hypothalamic knife cuts: Further evidence for a longitudinal feeding inhibitory pathway. J Comp Physiol Psychol 1977;91:1000-1018.

10 Victor M, Adams RD, Collins GH: The Wernicke-Korsakoff Syndrome. Philadelphia, Davis, 1971, pp 166-170. 